\title{
Total Synthesis of Ingenol
}

Andrew Nickel, Toru Maruyama, Haifeng Tang, Prescott D. Murphy, ${ }^{\ddagger}$ Blake Greene, ${ }^{\ddagger}$ Naeem Yusuff, and John L. Wood*

Sterling Chemistry Laboratory, Department of Chemistry, Yale University, New Haven, Connecticut 06520-8107

\section{Supplementary Information 2: Spectra}



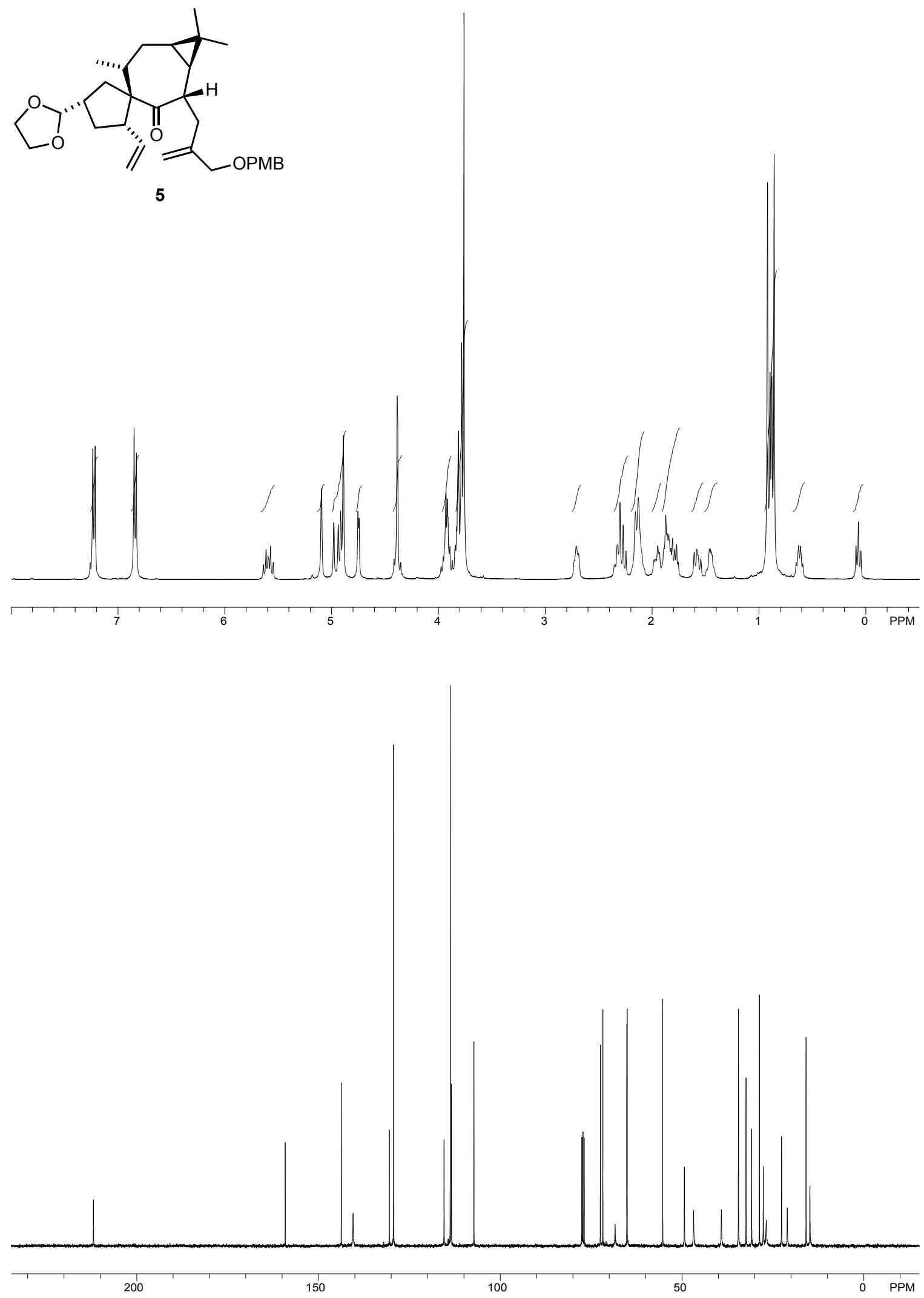

${ }^{1} \mathrm{H}(400 \mathrm{MHz})$ and ${ }^{13} \mathrm{C}$ NMR $(100 \mathrm{MHz})$ of compound $5\left(\mathrm{CDCl}_{3}\right)$ 


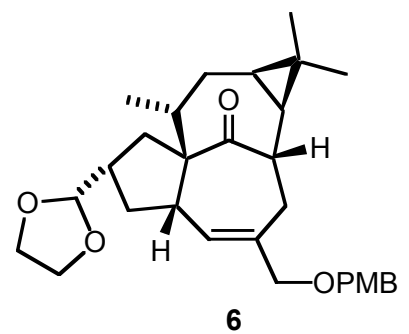

6
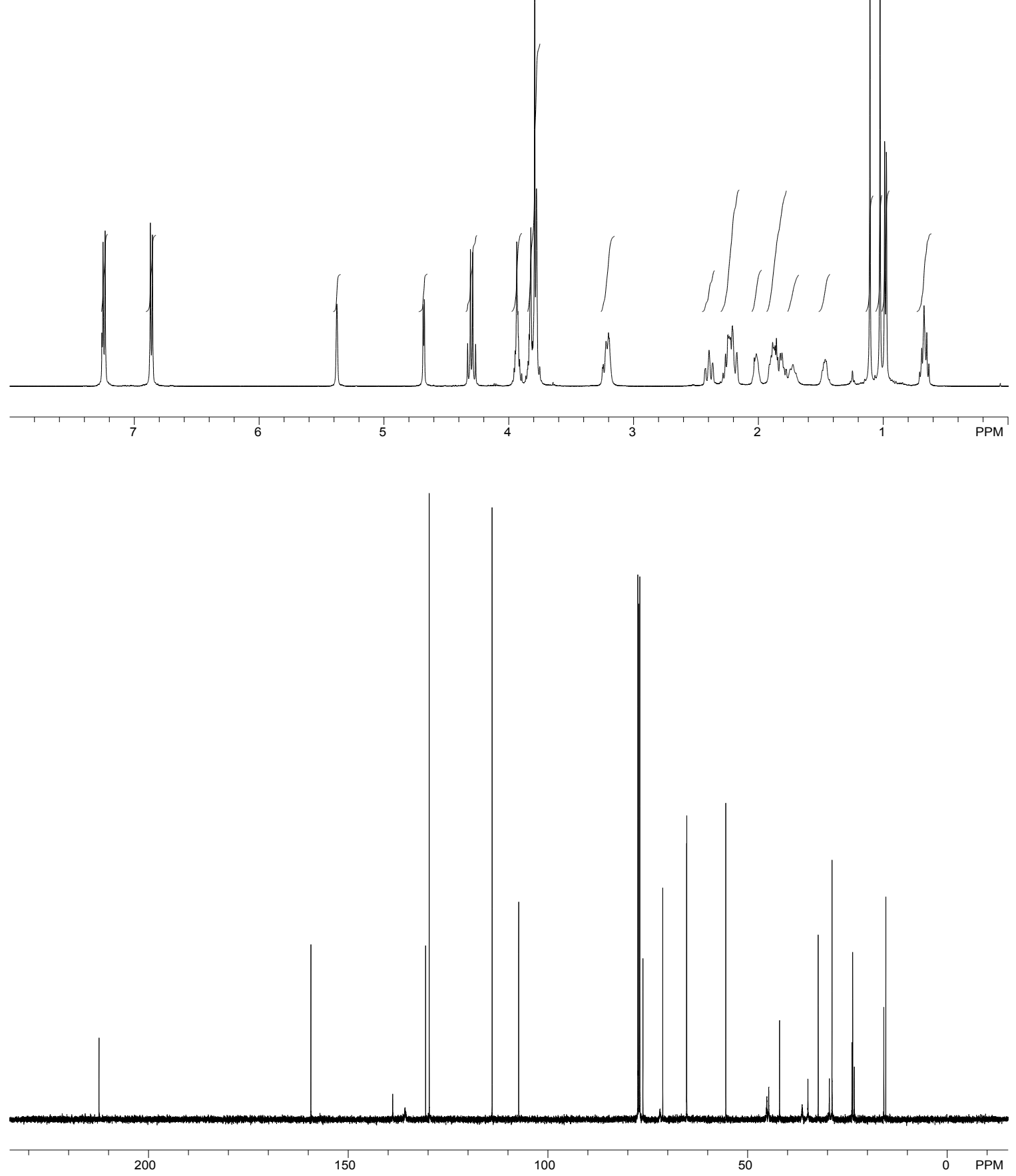

${ }^{1} \mathrm{H}(500 \mathrm{MHz})$ and ${ }^{13} \mathrm{C}$ NMR $(125 \mathrm{MHz})$ of compound $\mathbf{6}\left(\mathrm{CDCl}_{3}\right)$ 

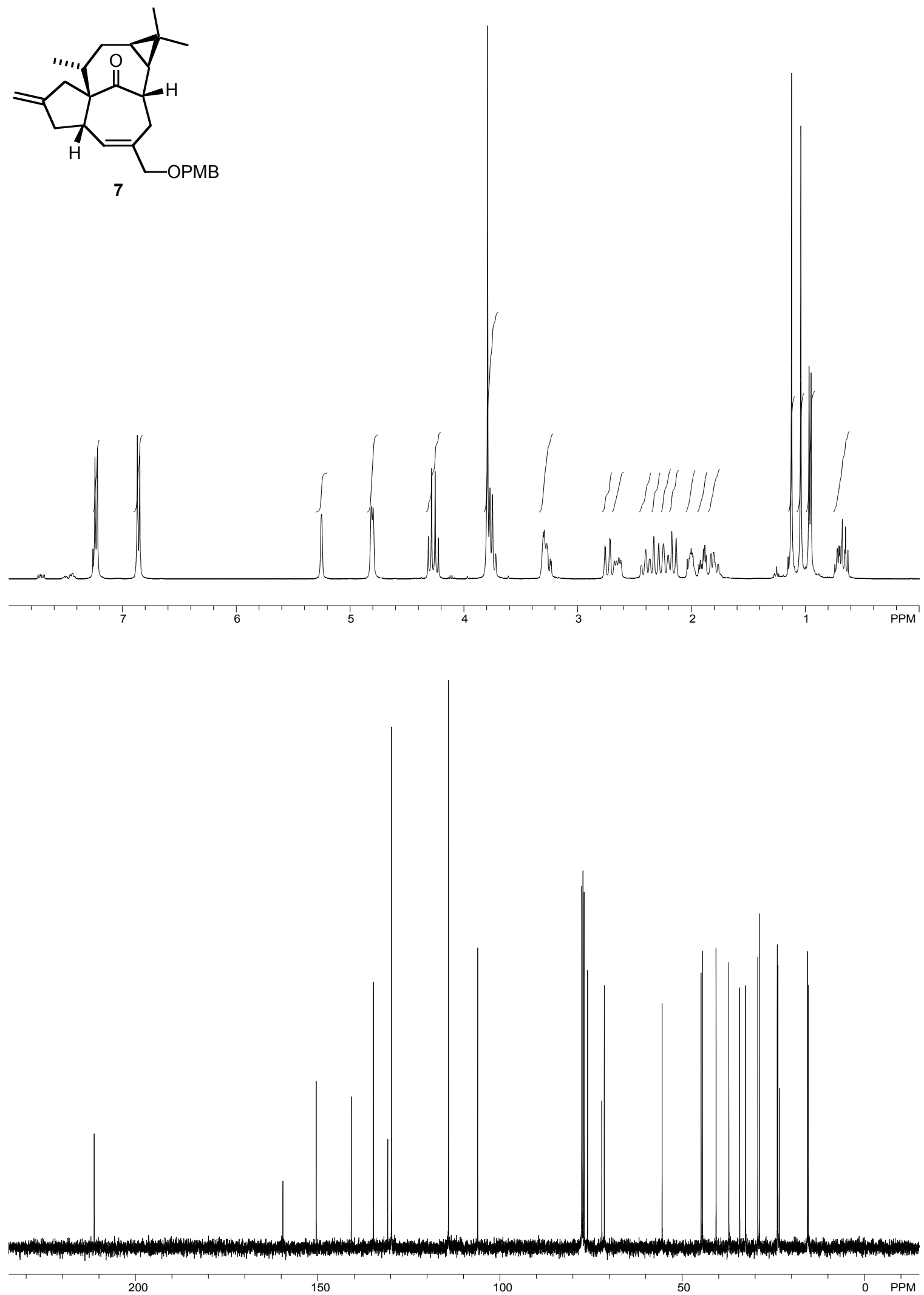

${ }^{1} \mathrm{H}(400 \mathrm{MHz})$ and ${ }^{13} \mathrm{C}$ NMR $(100 \mathrm{MHz})$ of compound $7\left(\mathrm{CDCl}_{3}\right)$ 

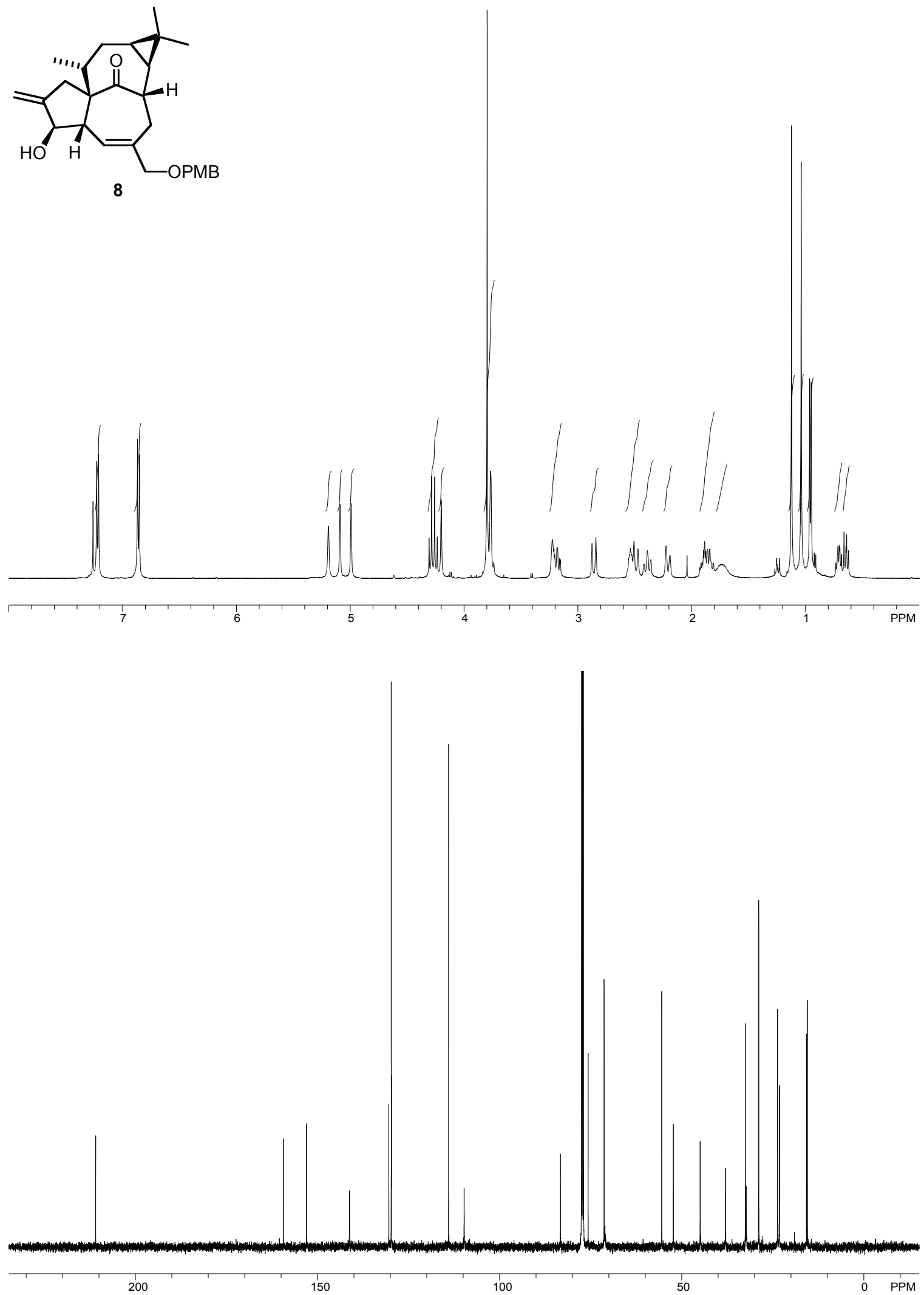

${ }^{1} \mathrm{H}(500 \mathrm{MHz})$ and ${ }^{13} \mathrm{C}$ NMR $(125 \mathrm{MHz})$ of compound $8\left(\mathrm{CDCl}_{3}\right)$ 

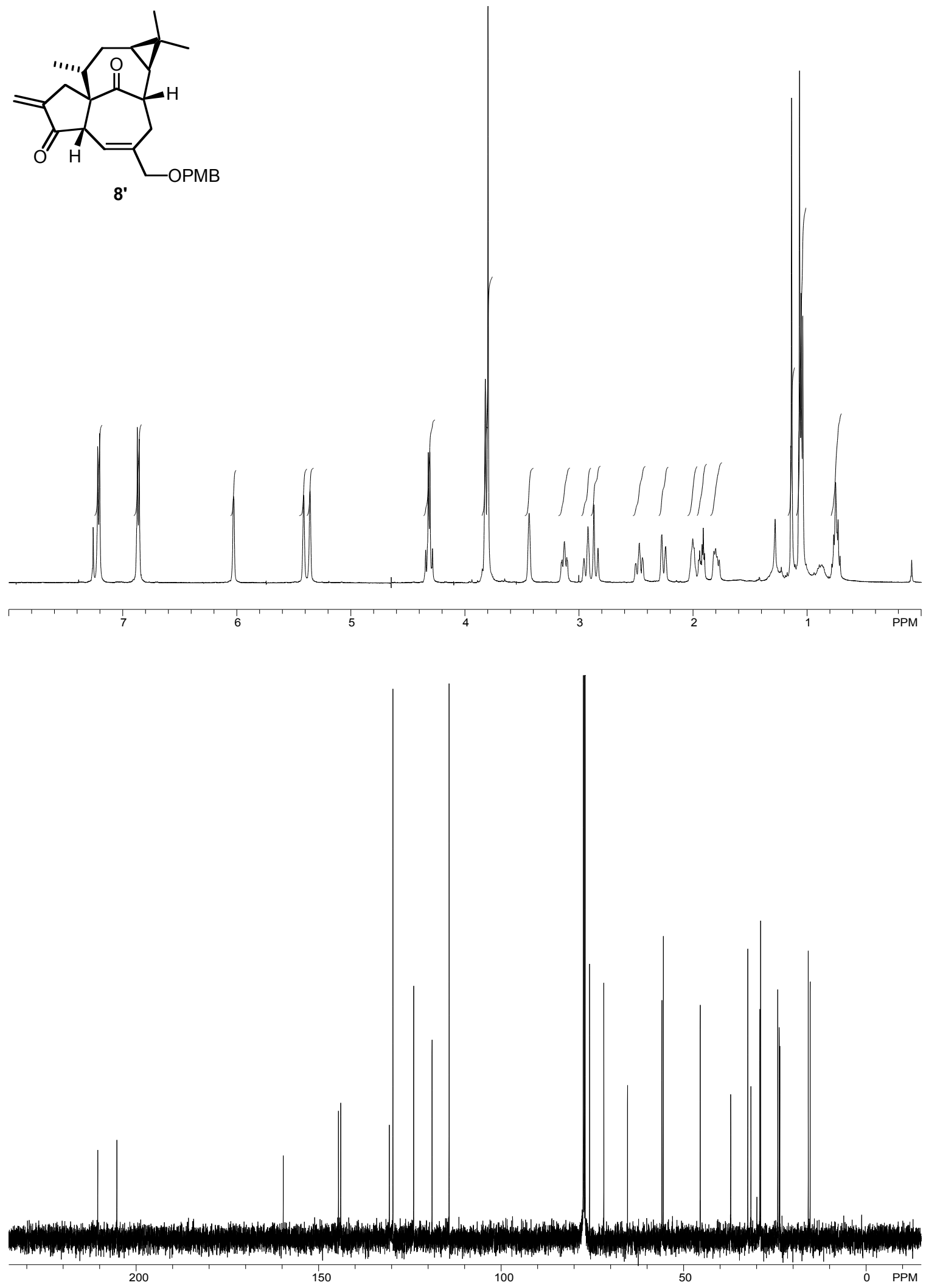

${ }^{1} \mathrm{H}(500 \mathrm{MHz})$ and ${ }^{13} \mathrm{C} \mathrm{NMR}(125 \mathrm{MHz})$ of compound $\mathbf{8}^{\prime}\left(\mathrm{CDCl}_{3}, 50^{\circ} \mathrm{C}\right)$ 

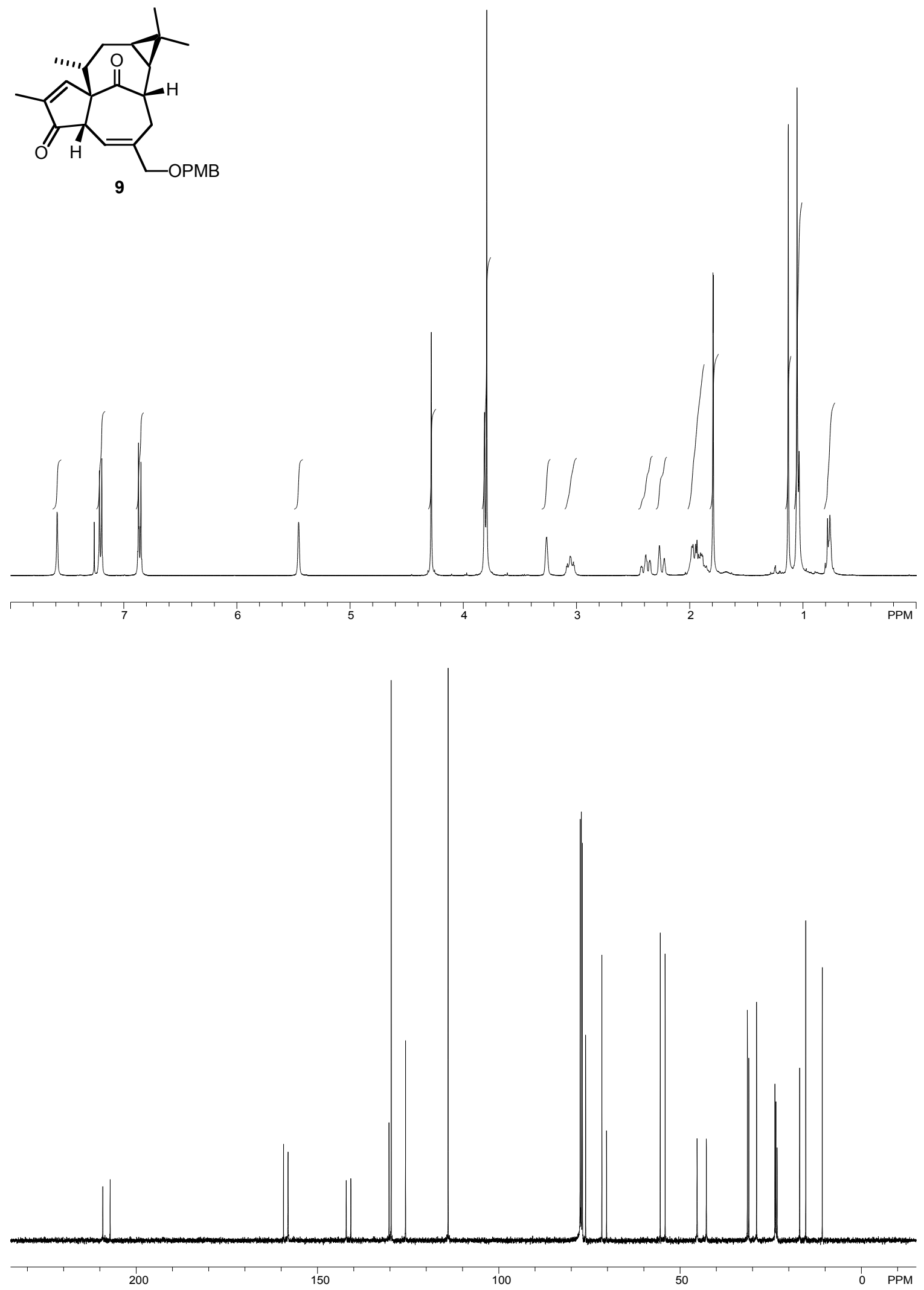

${ }^{1} \mathrm{H}(400 \mathrm{MHz})$ and ${ }^{13} \mathrm{C}$ NMR $(100 \mathrm{MHz})$ of compound $9\left(\mathrm{CDCl}_{3}\right)$ 

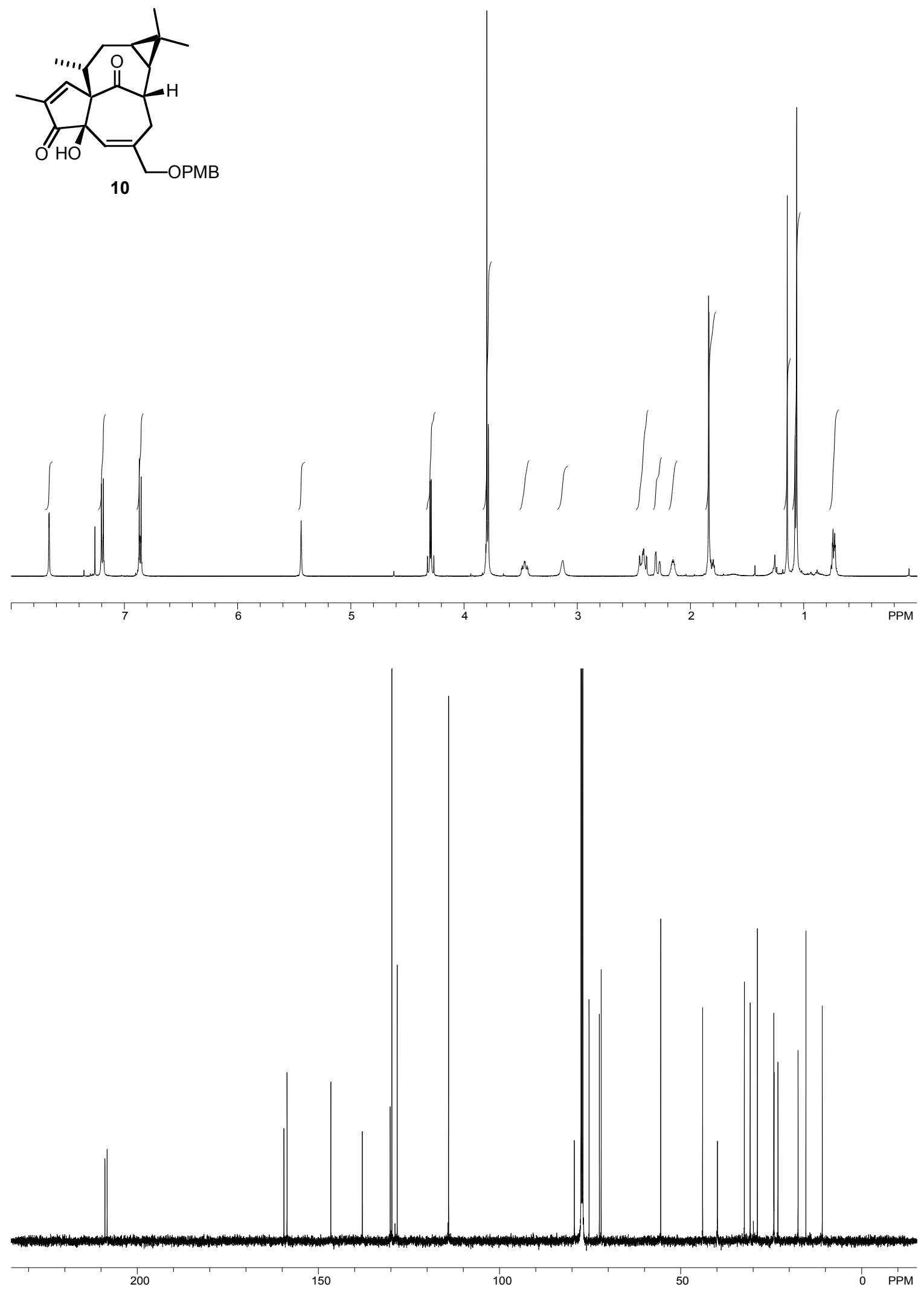

${ }^{1} \mathrm{H}(500 \mathrm{MHz})$ and ${ }^{13} \mathrm{C}$ NMR $(125 \mathrm{MHz})$ of compound $\mathbf{1 0}\left(\mathrm{CDCl}_{3}\right)$ 

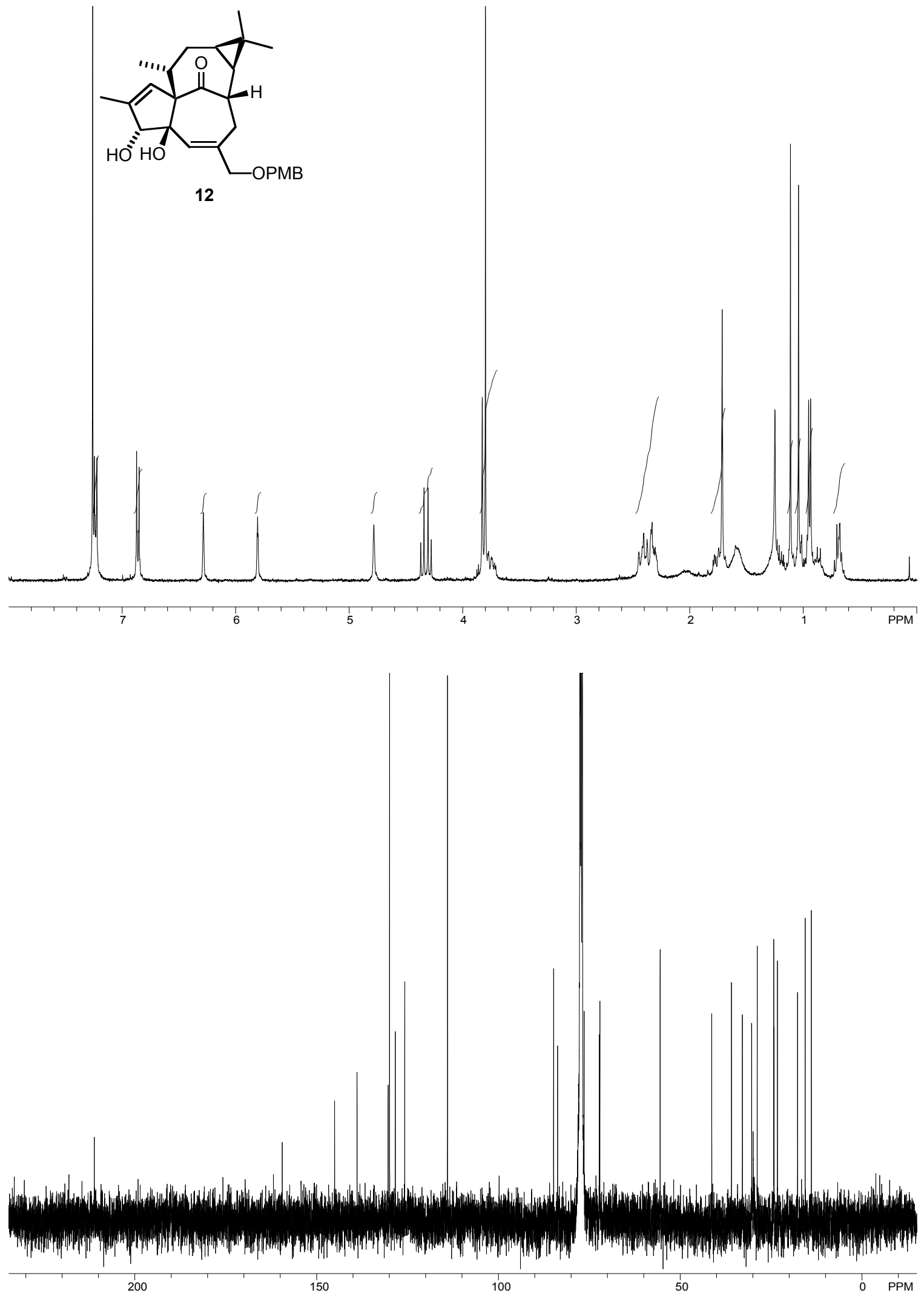

${ }^{1} \mathrm{H}(400 \mathrm{MHz})$ and ${ }^{13} \mathrm{C}$ NMR $(100 \mathrm{MHz})$ of compound $12\left(\mathrm{CDCl}_{3}\right)$ 

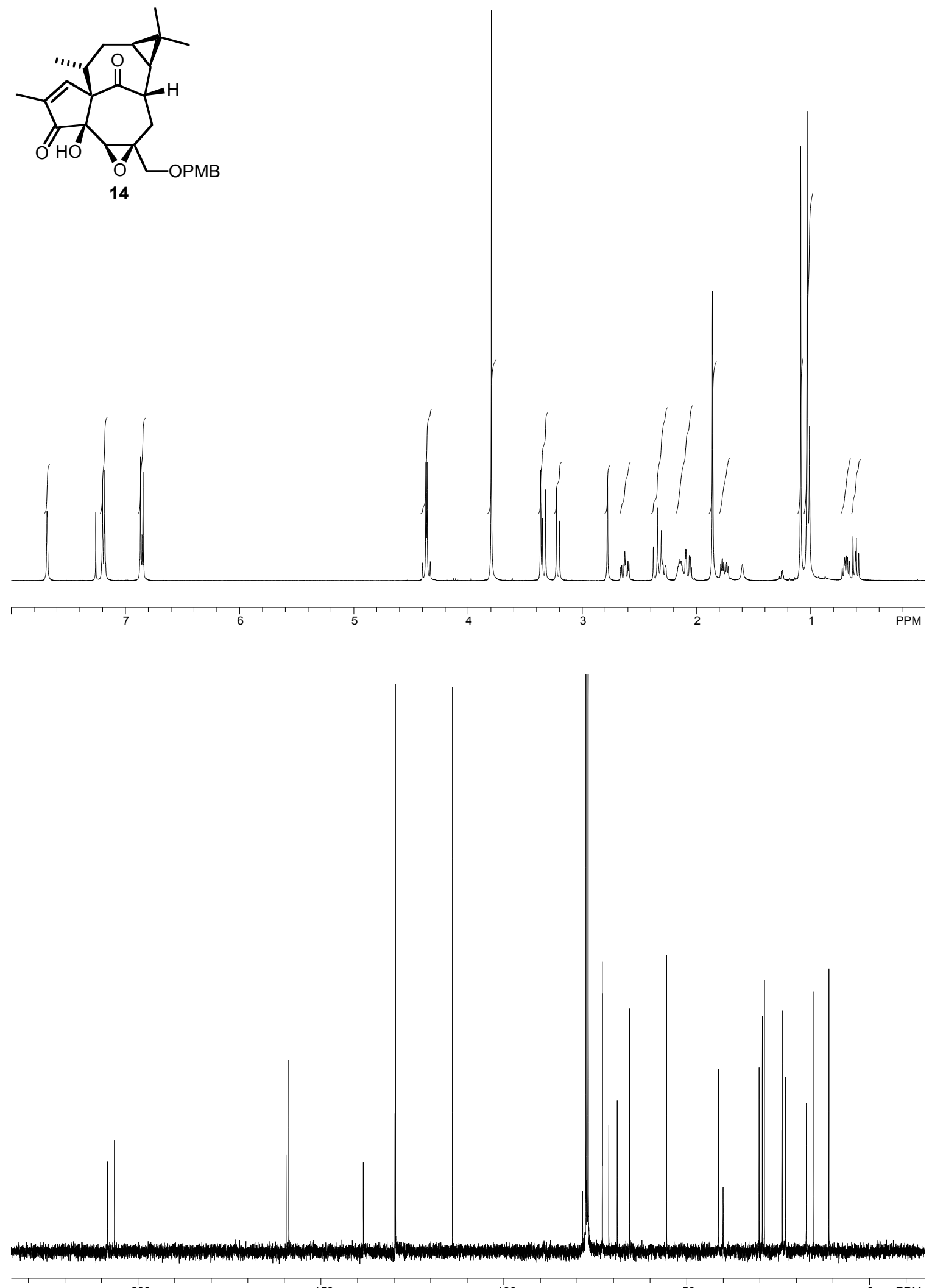

200

${ }^{1} \mathrm{H}(400 \mathrm{MHz})$ and ${ }^{13} \mathrm{C}$ NMR $(100 \mathrm{MHz})$ of compound $14\left(\mathrm{CDCl}_{3}\right)$ 

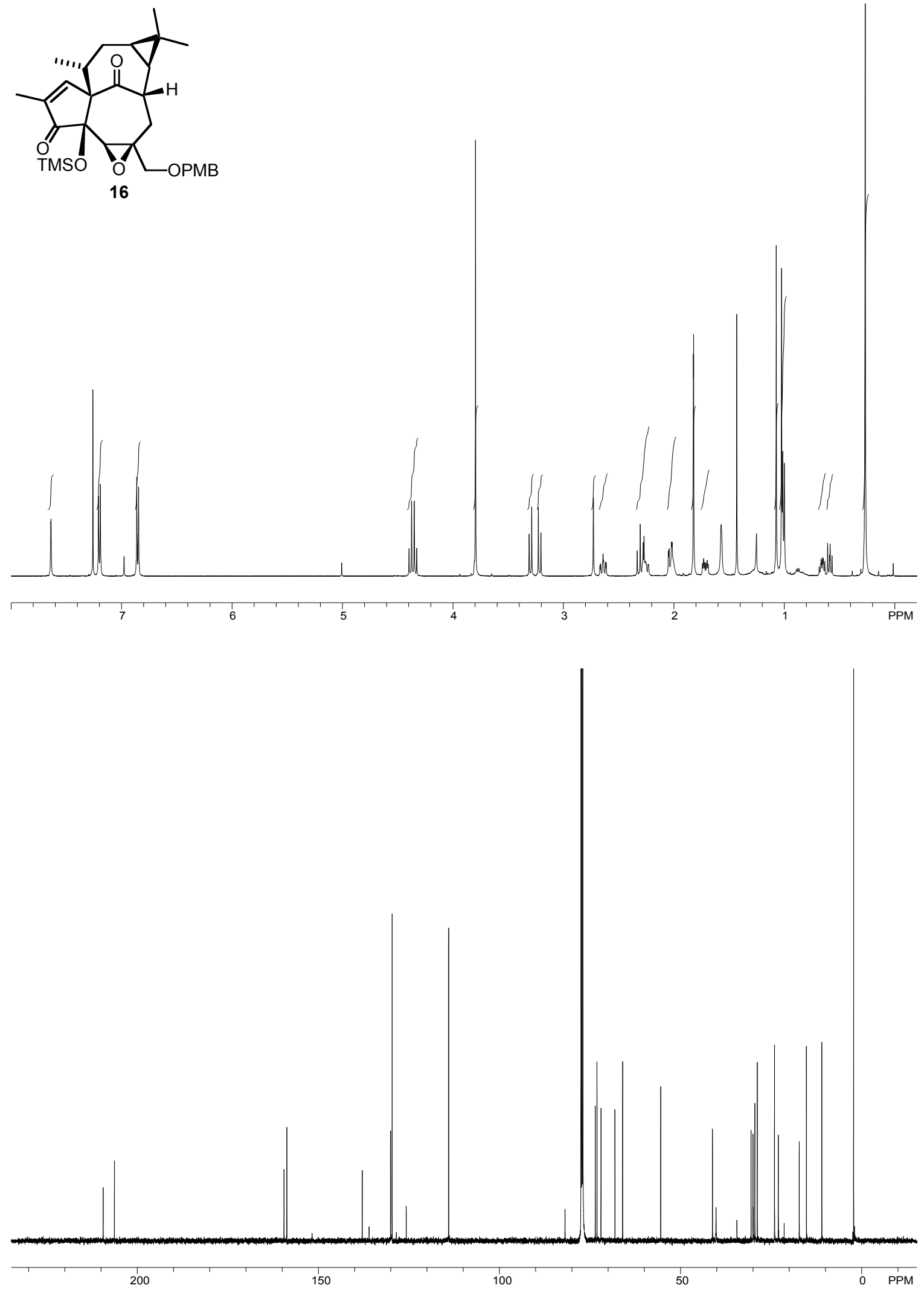

${ }^{1} \mathrm{H}(500 \mathrm{MHz})$ and ${ }^{13} \mathrm{C}$ NMR $(125 \mathrm{MHz})$ of compound $\mathbf{1 6}\left(\mathrm{CDCl}_{3}\right)$ 

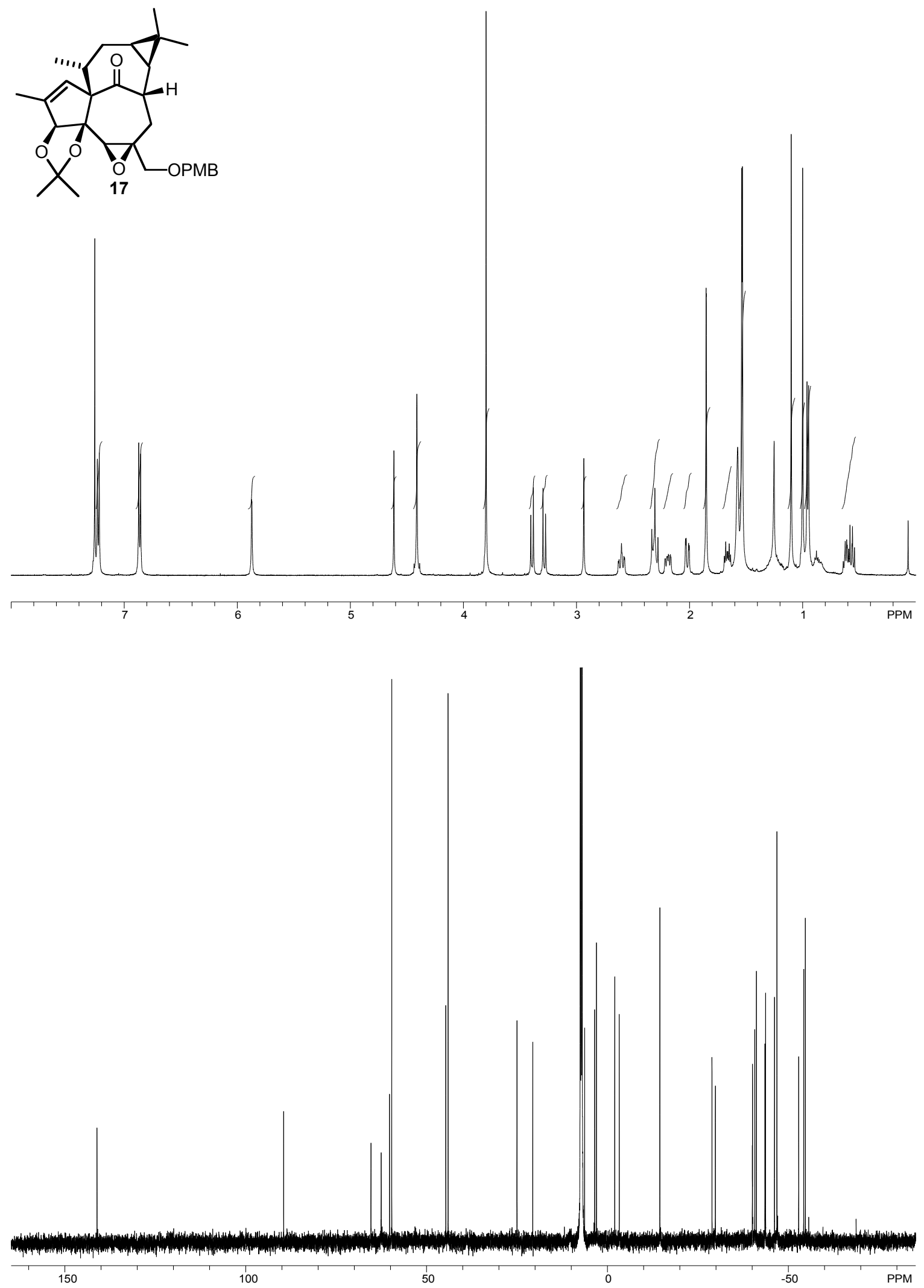

${ }^{1} \mathrm{H}(500 \mathrm{MHz})$ and ${ }^{13} \mathrm{C}$ NMR $(125 \mathrm{MHz})$ of compound $17\left(\mathrm{CDCl}_{3}\right)$ 

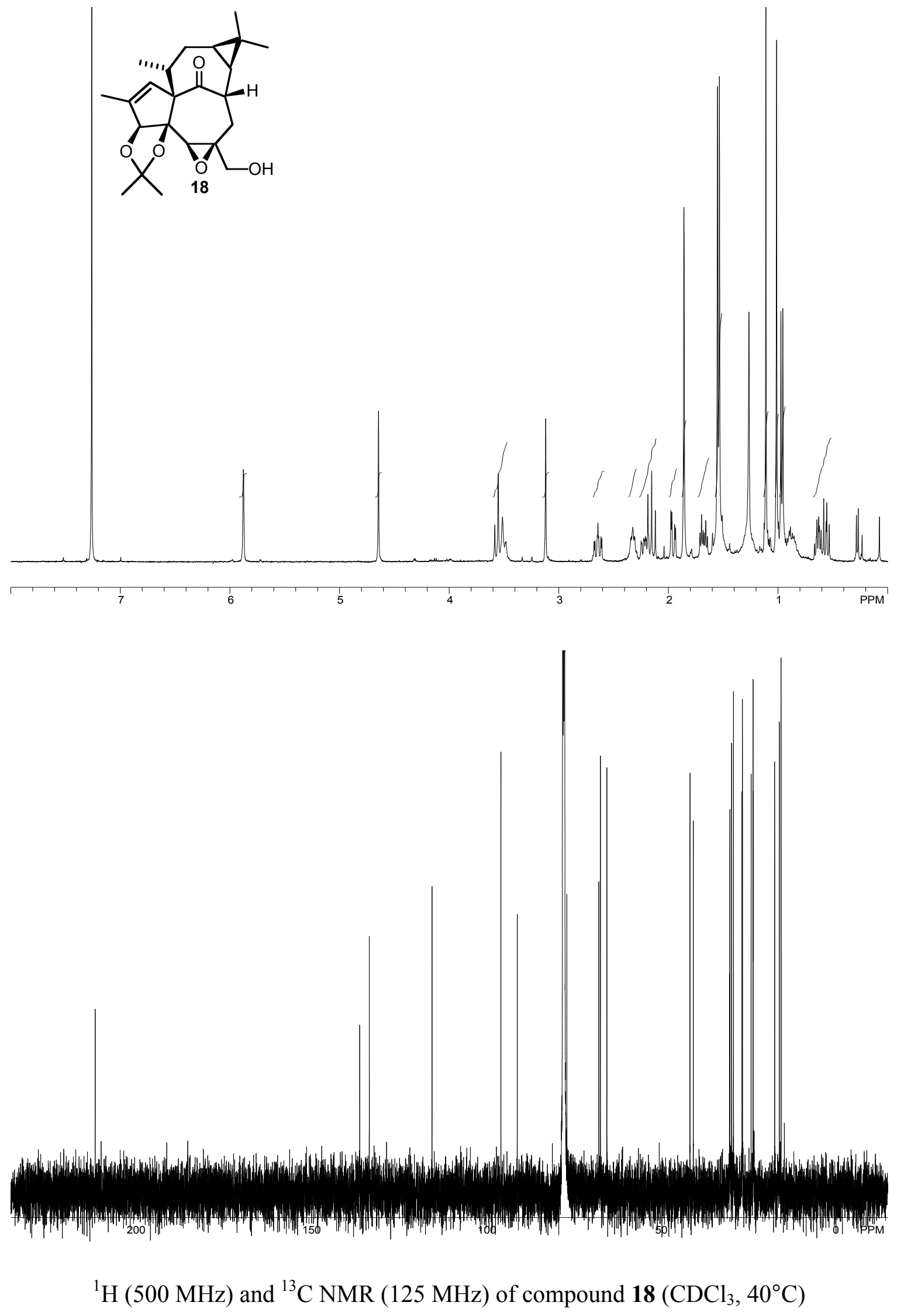

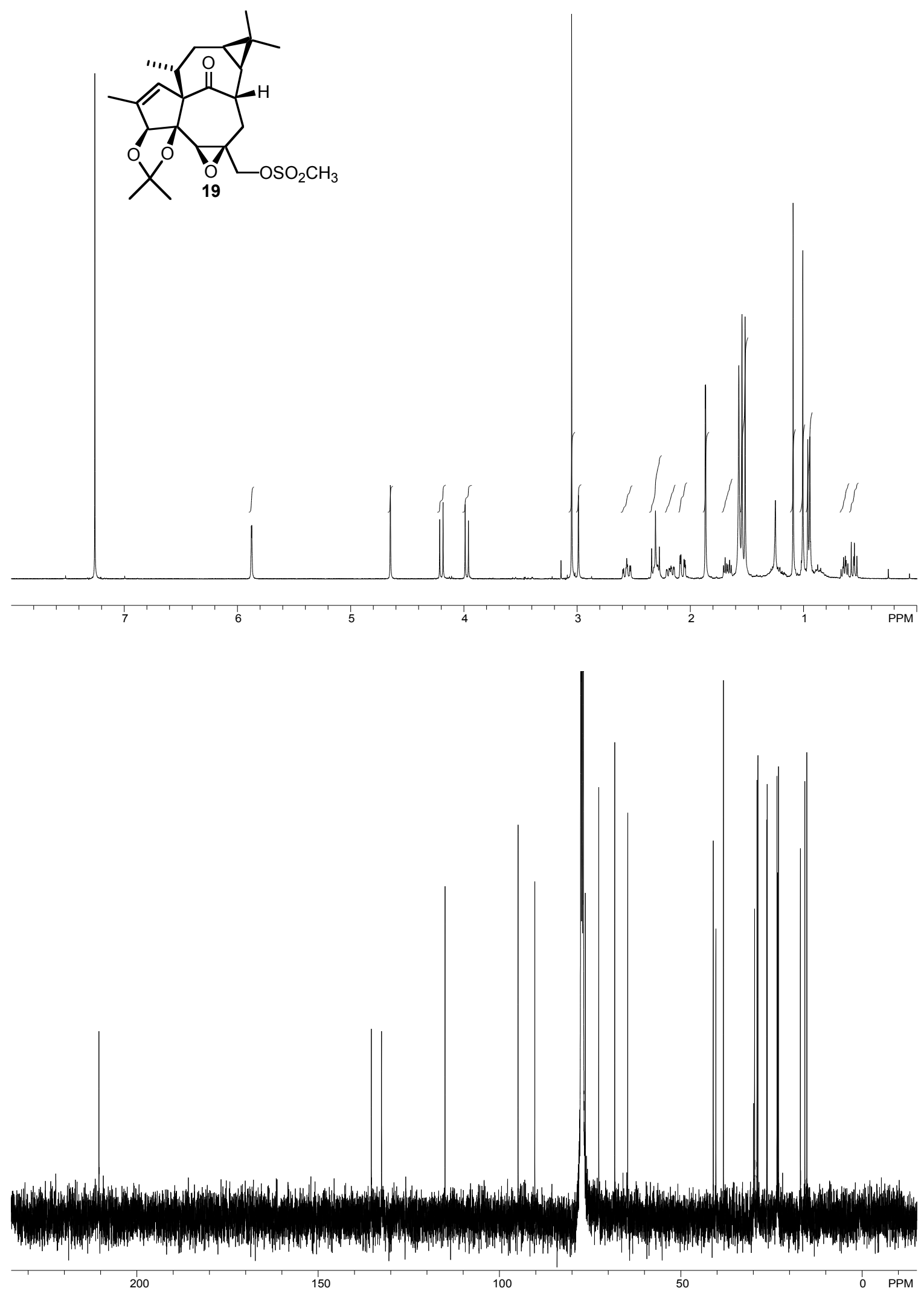

${ }^{1} \mathrm{H}(400 \mathrm{MHz})$ and ${ }^{13} \mathrm{C}$ NMR $(100 \mathrm{MHz})$ of compound $19\left(\mathrm{CDCl}_{3}\right)$ 

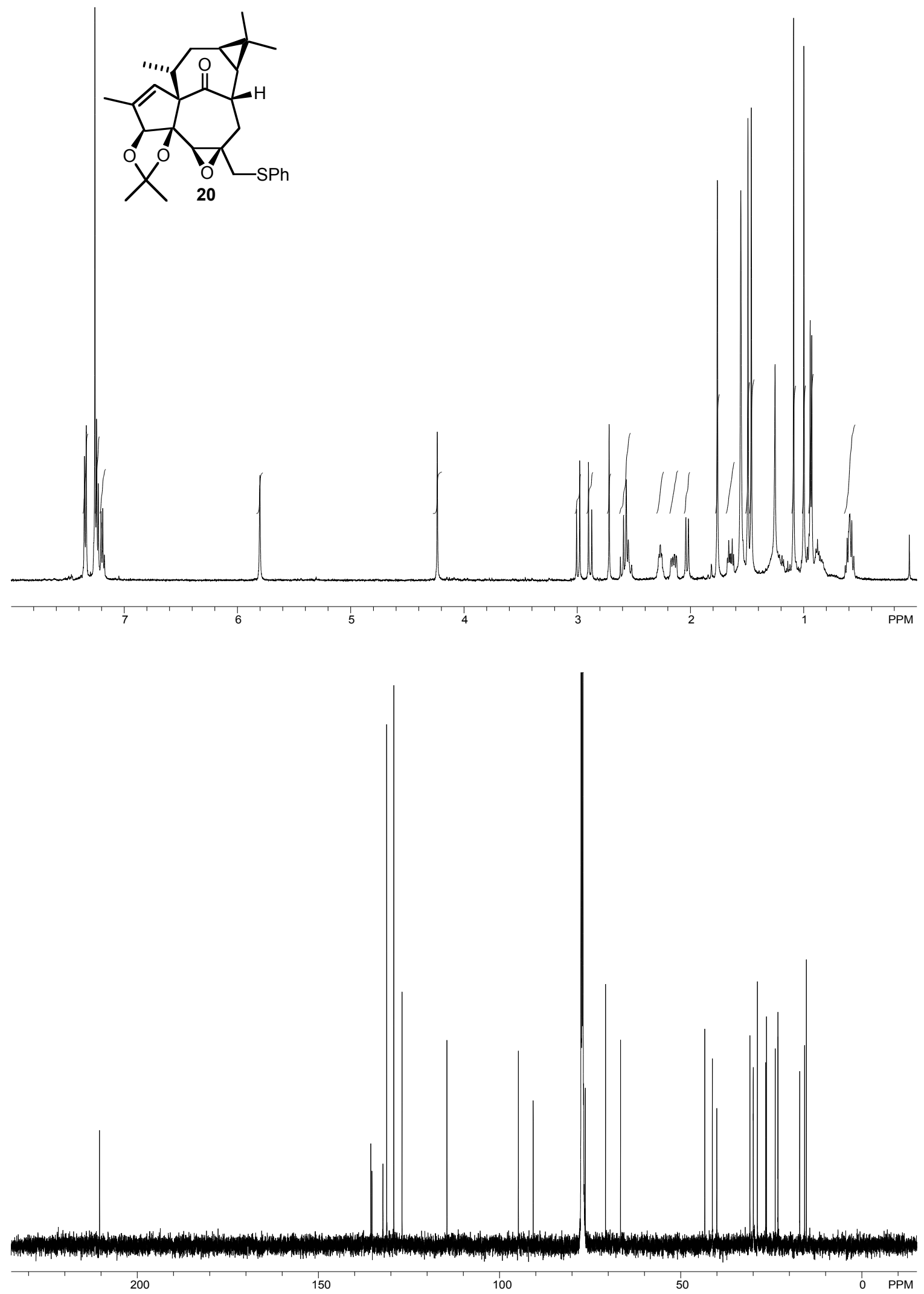

${ }^{1} \mathrm{H}(500 \mathrm{MHz})$ and ${ }^{13} \mathrm{C} \mathrm{NMR}(125 \mathrm{MHz})$ of compound $20\left(\mathrm{CDCl}_{3}\right)$ 


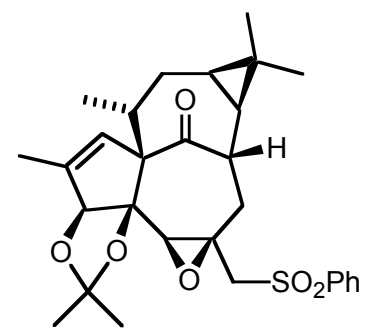

21
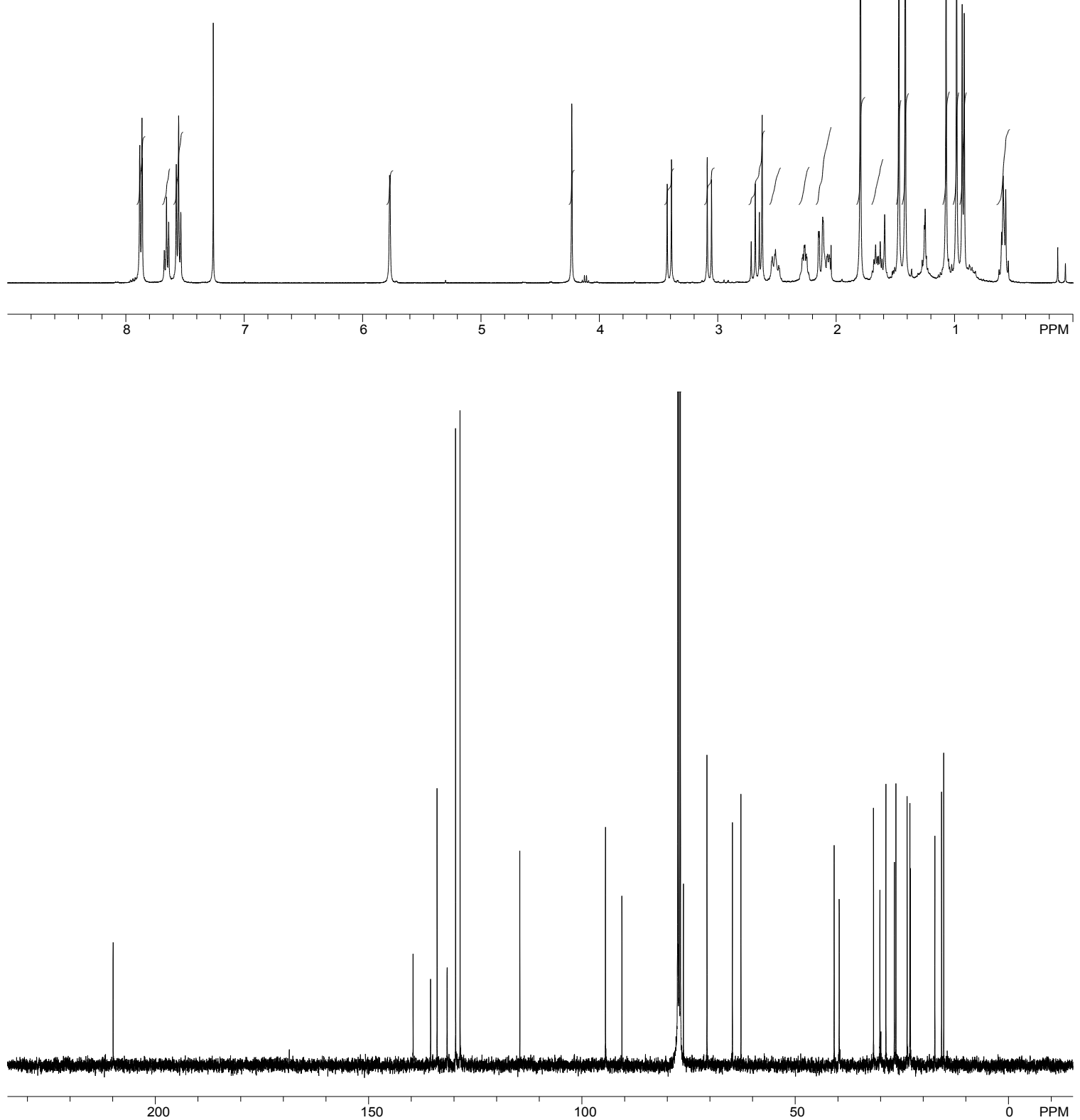

${ }^{1} \mathrm{H}(400 \mathrm{MHz})$ and ${ }^{13} \mathrm{C}$ NMR $(100 \mathrm{MHz})$ of compound $21\left(\mathrm{CDCl}_{3}\right)$ 

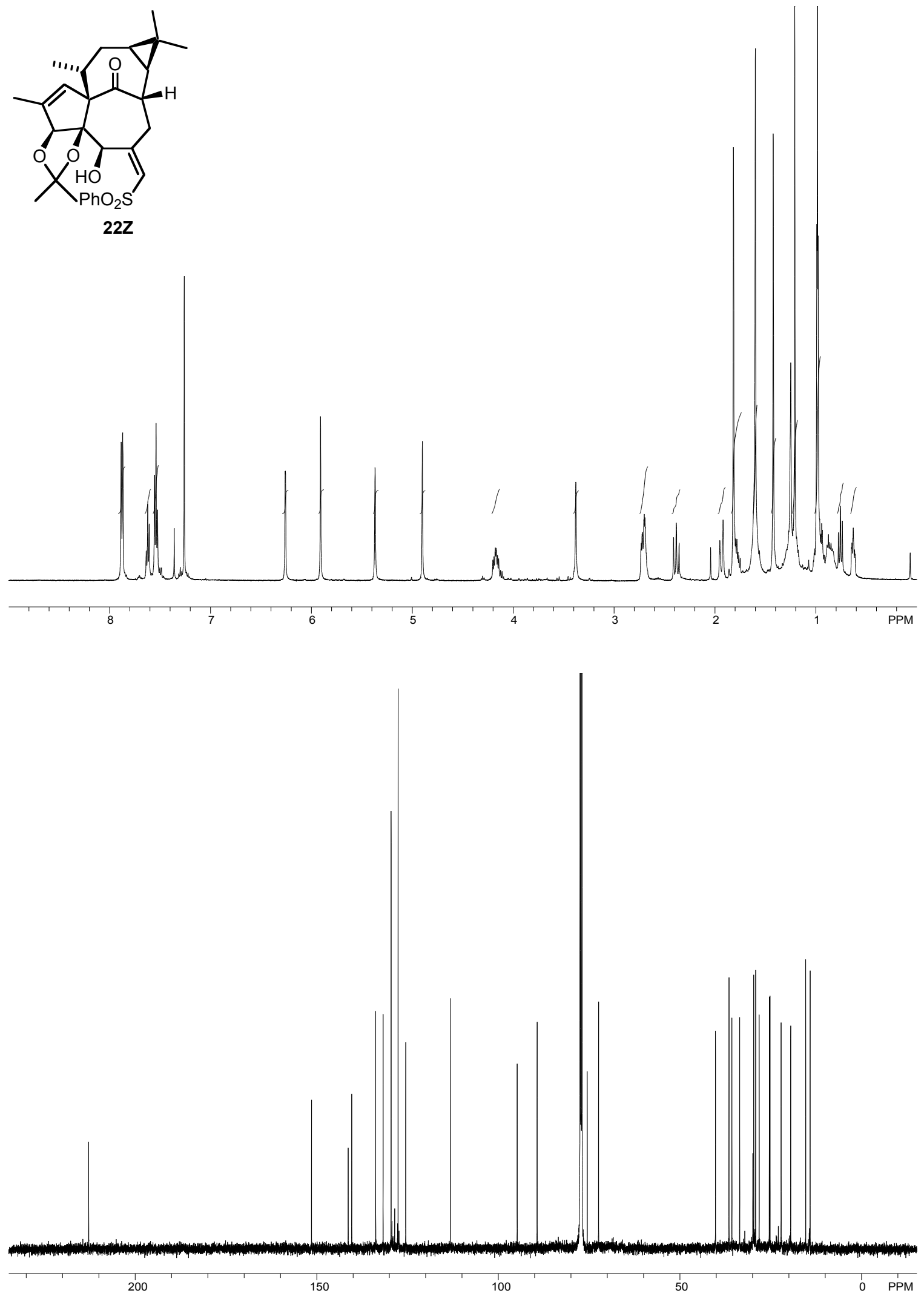

${ }^{1} \mathrm{H}(500 \mathrm{MHz})$ and ${ }^{13} \mathrm{C} \mathrm{NMR}(125 \mathrm{MHz})$ of compound $22 \mathrm{Z}\left(\mathrm{CDCl}_{3}\right)$ 

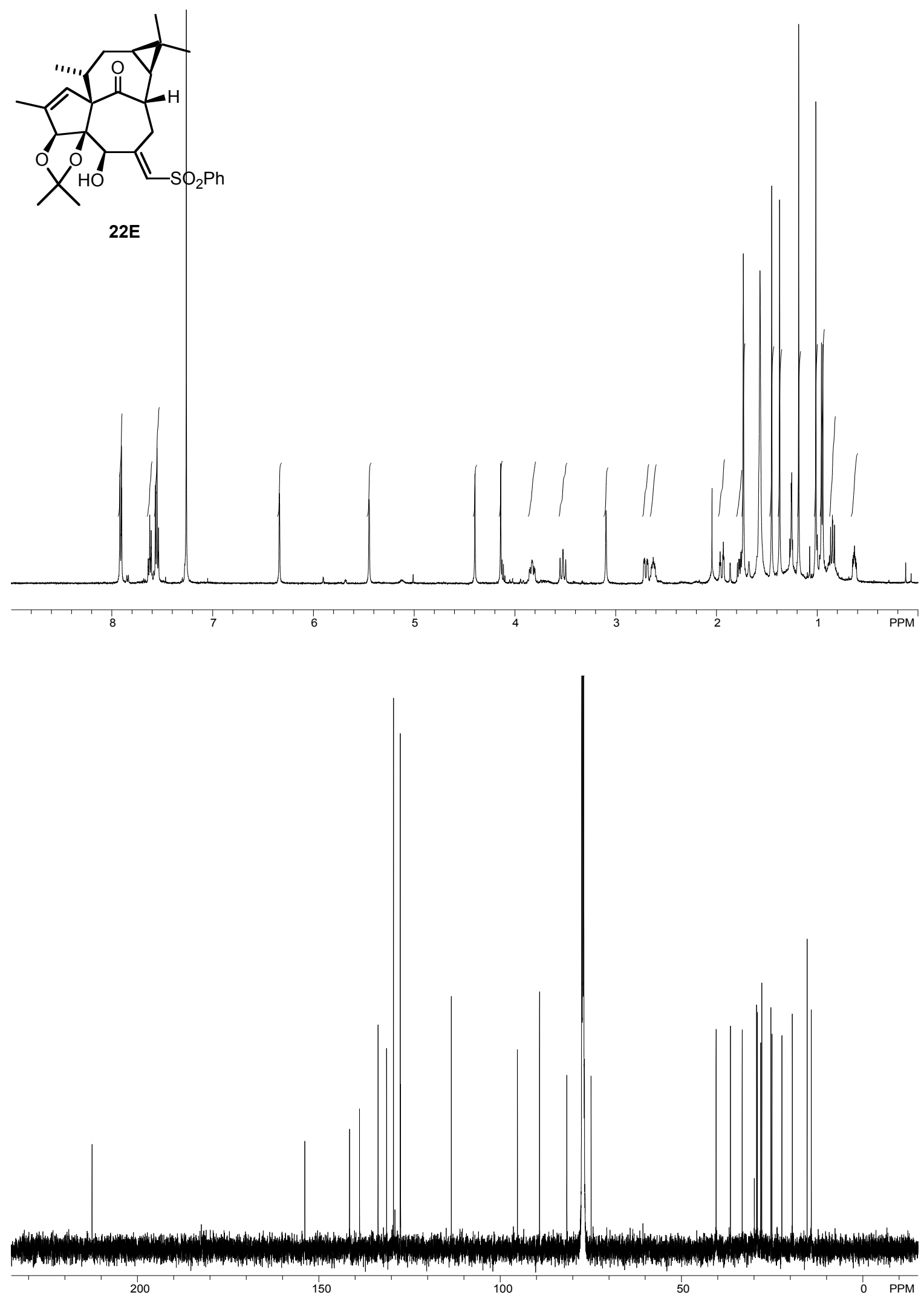

${ }^{1} \mathrm{H}(500 \mathrm{MHz})$ and ${ }^{13} \mathrm{C} \mathrm{NMR}(125 \mathrm{MHz})$ of compound $22 \mathbf{E}\left(\mathrm{CDCl}_{3}\right)$ 


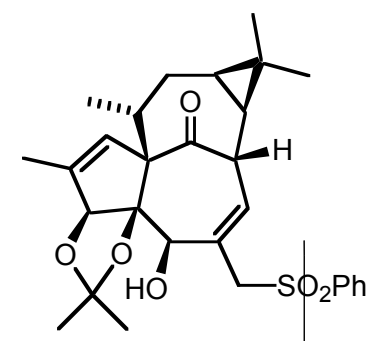

23
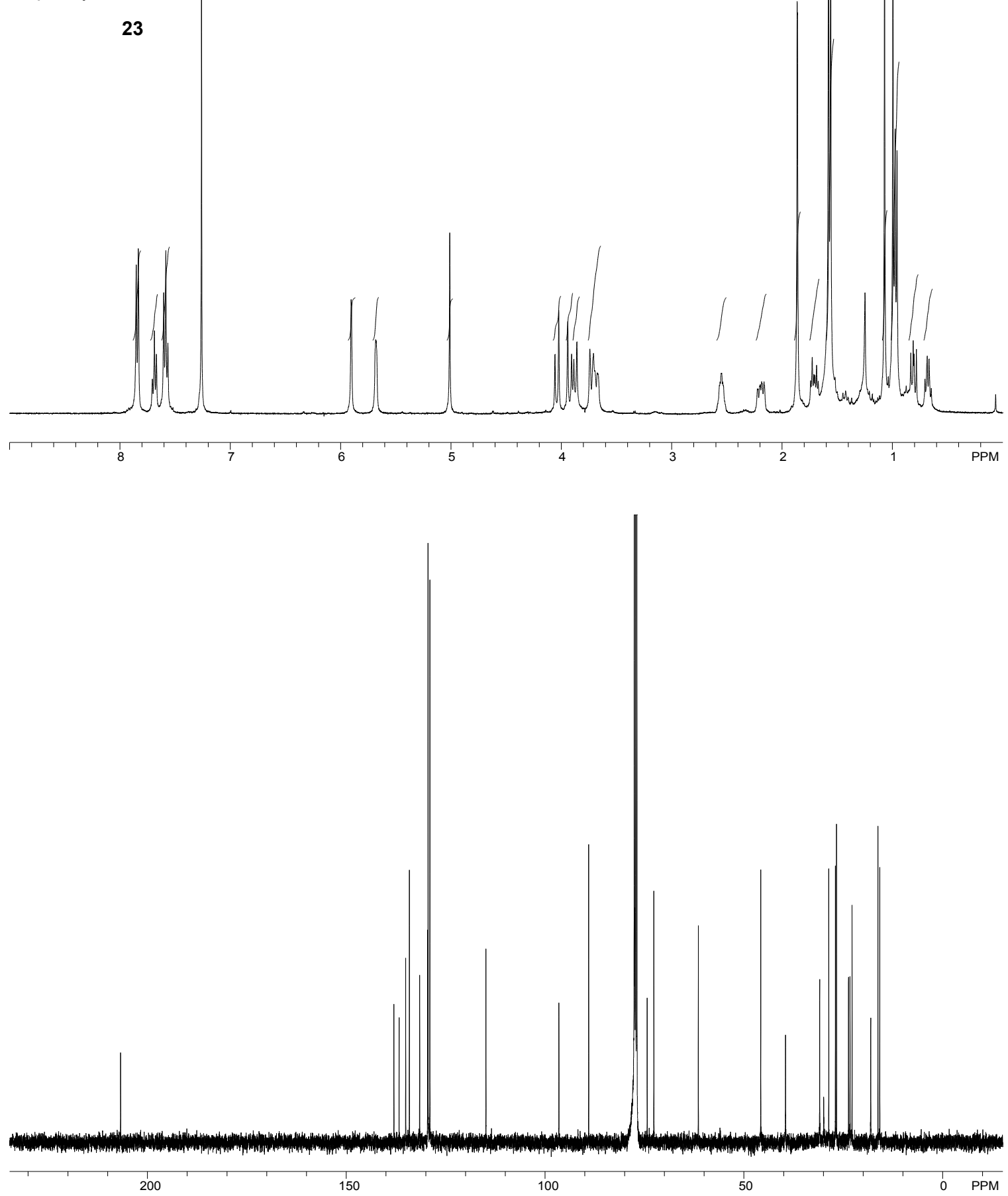

${ }^{1} \mathrm{H}(400 \mathrm{MHz})$ and ${ }^{13} \mathrm{C}$ NMR $(100 \mathrm{MHz})$ of compound $23\left(\mathrm{CDCl}_{3}\right)$ 

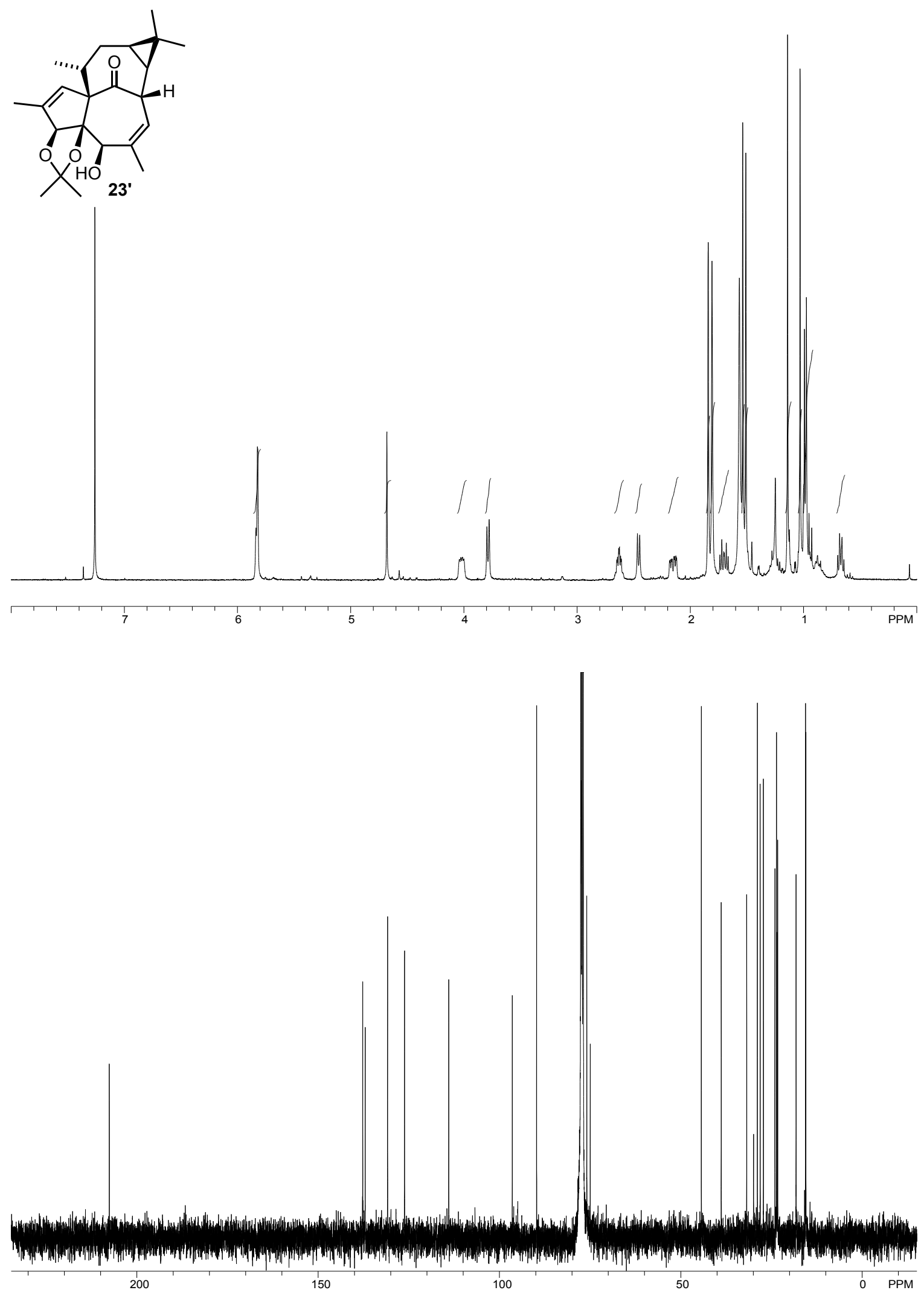

${ }^{1} \mathrm{H}(400 \mathrm{MHz})$ and ${ }^{13} \mathrm{C}$ NMR $(100 \mathrm{MHz})$ of compound $\mathbf{2 3}^{\prime}\left(\mathrm{CDCl}_{3}\right)$ 

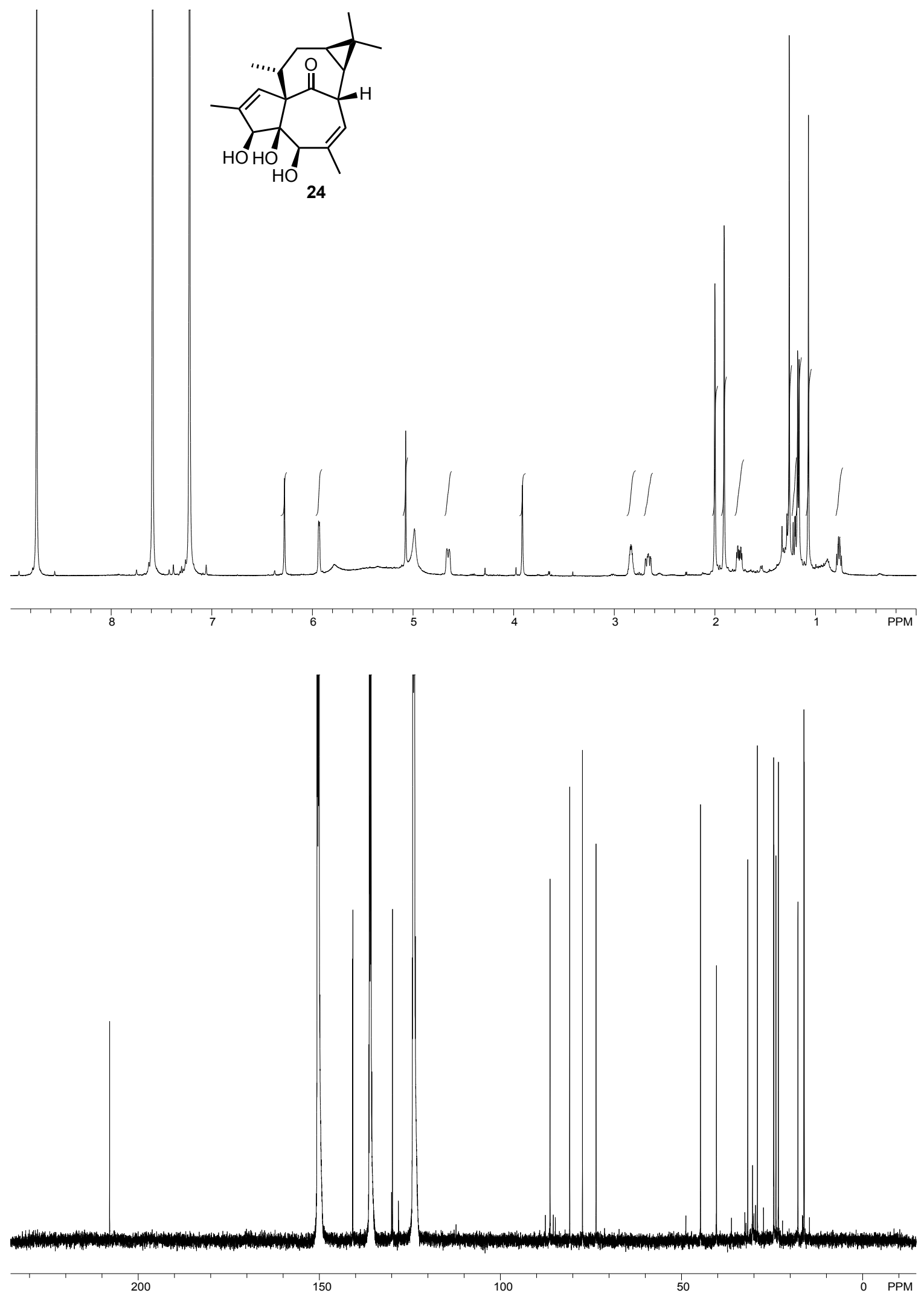

${ }^{1} \mathrm{H}(500 \mathrm{MHz})$ and ${ }^{13} \mathrm{C}$ NMR $(125 \mathrm{MHz})$ of compound $24\left(\mathrm{C}_{5} \mathrm{D}_{5} \mathrm{~N}\right)$ 

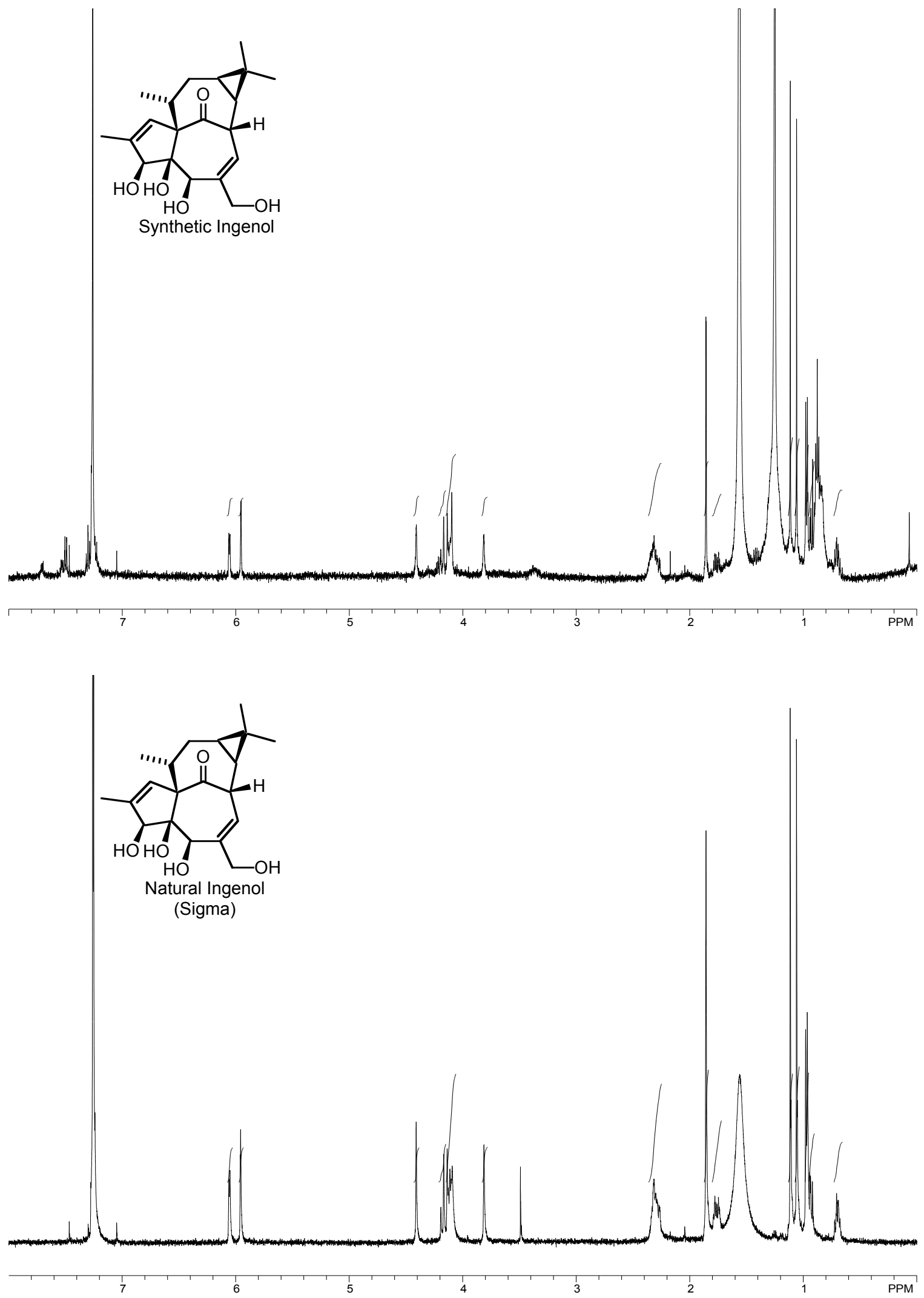

${ }^{1} \mathrm{H}$ NMR $\left(\mathrm{CDCl}_{3}, 500 \mathrm{MHz}\right)$ of ingenol 

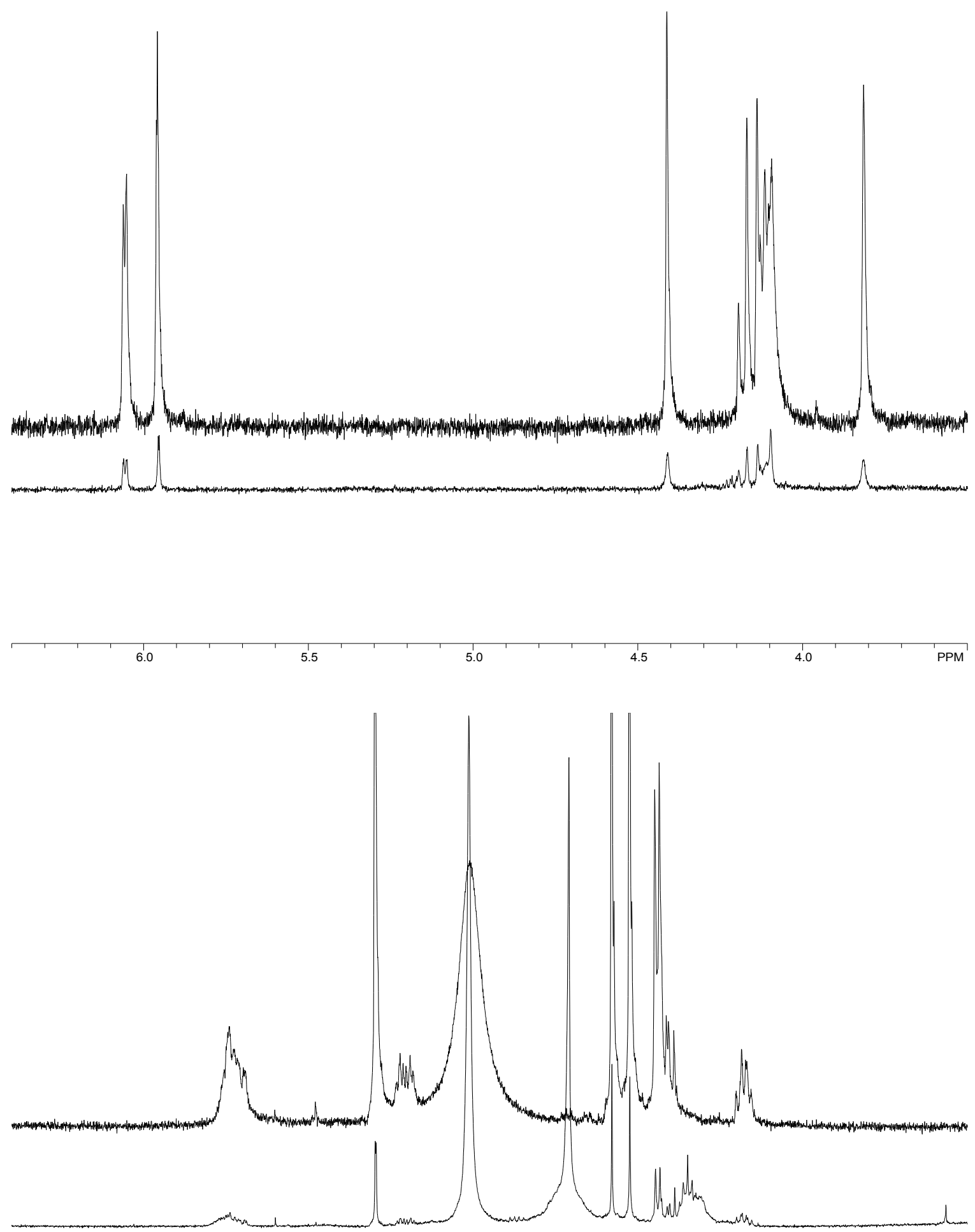

Natural ingenol over synthetic ingenol 


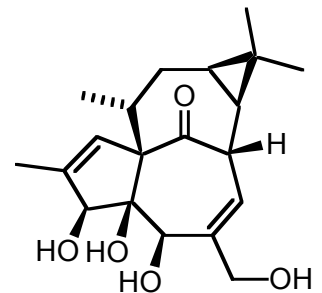

Synthetic Ingenol
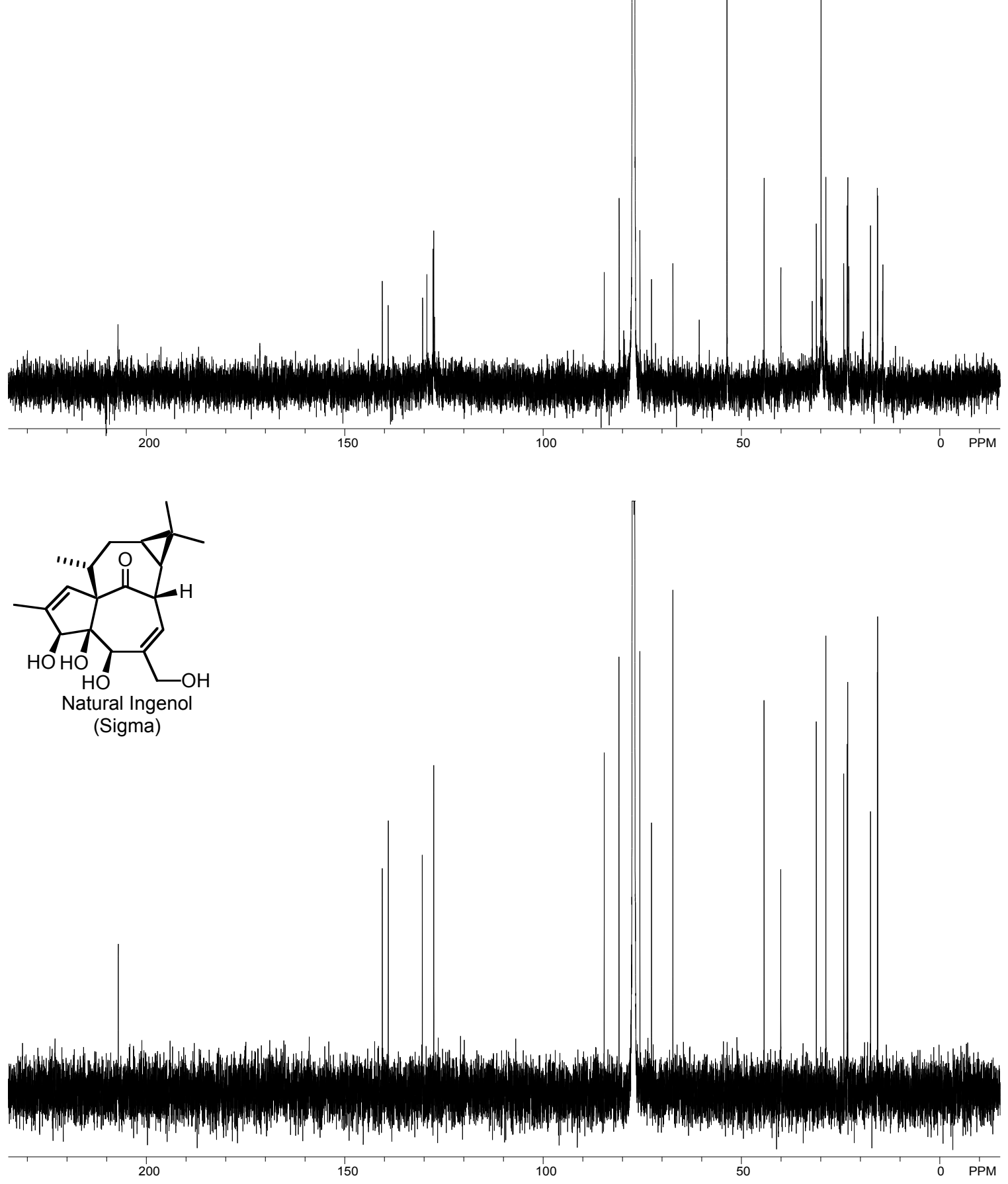

${ }^{13} \mathrm{C} \mathrm{NMR}\left(\mathrm{CDCl}_{3}, 125 \mathrm{MHz}\right)$ of ingenol 

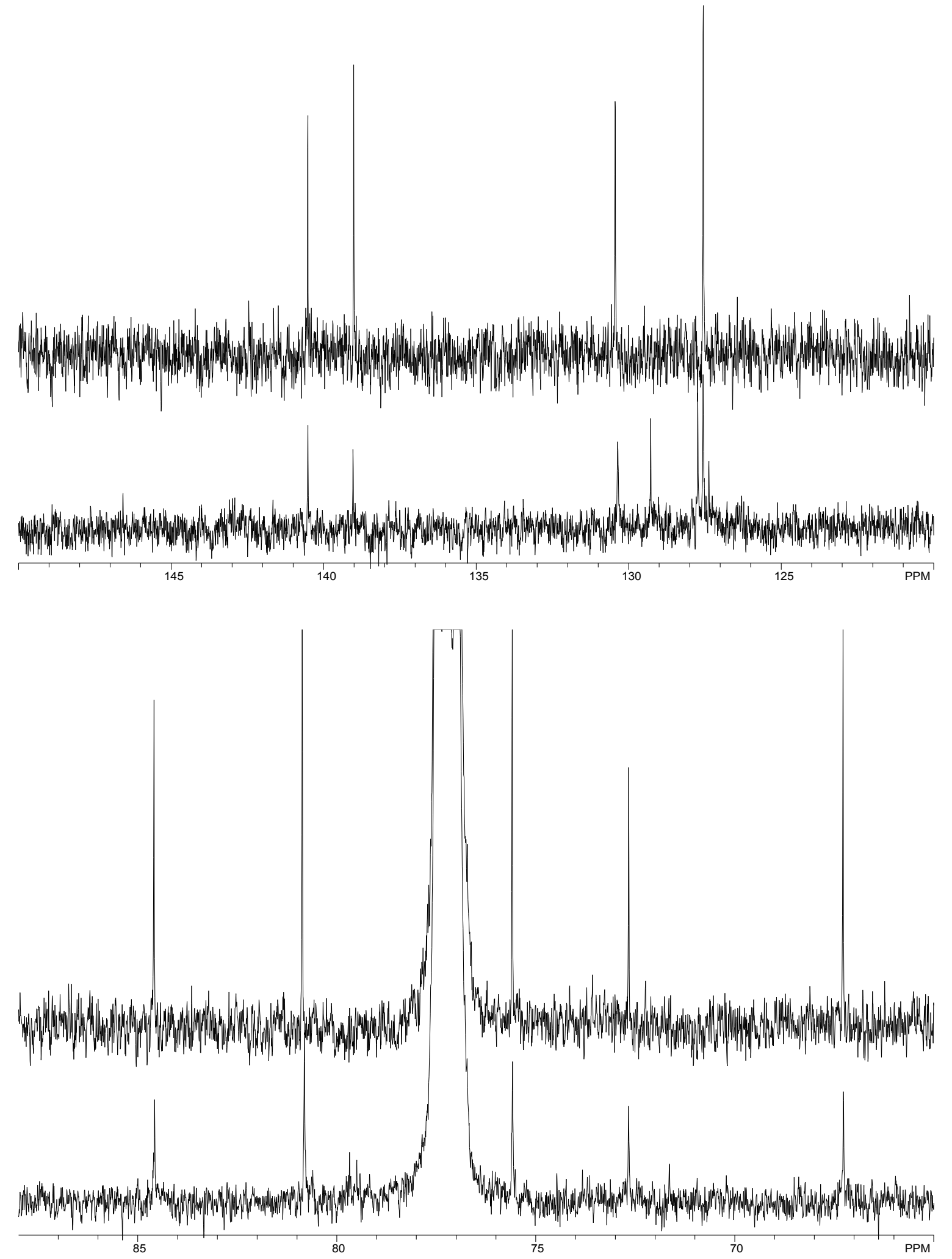

Natural ingenol over synthetic ingenol 


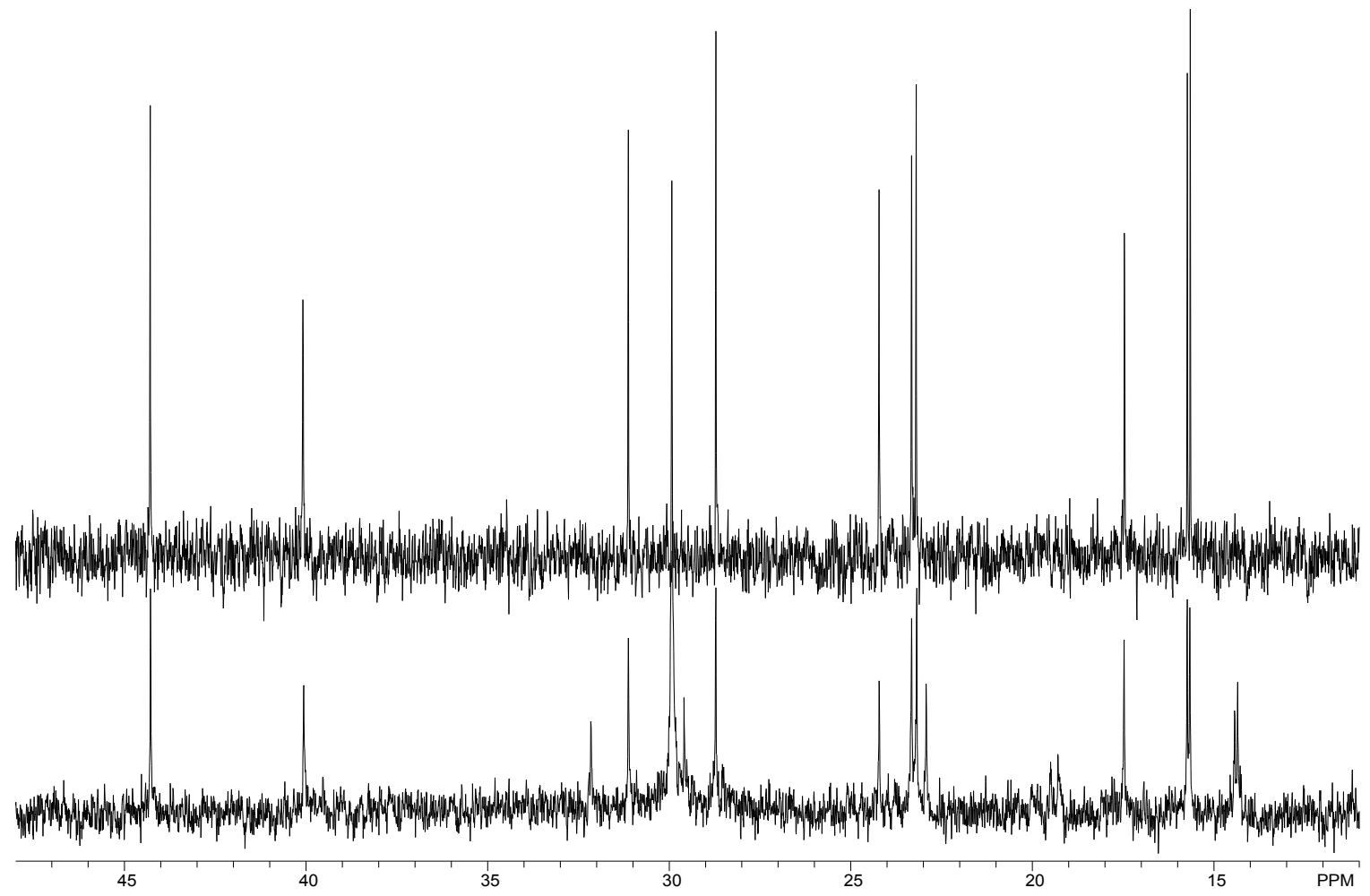

Natural ingenol over synthetic ingenol 